\title{
Formação inicial docente: análise de projetos pedagógicos de curso e suas relações com as tecnologias digitais
}

Juliana Brandão Machado - PPGEdu/UNIPAMPA - julianamachado@ unipampa.edu.br Grazielle de Souza Brandão - UNIPAMPA - grazisbran@gmail.com

Resumo: Este artigo tem o objetivo de analisar os currículos de cursos de licenciatura de uma universidade pública, a fim de perceber as suas relações com as tecnologias digitais. Problematiza a ideia de que a formação docente precisa estar alinhada às concepções contemporâneas, incluindo neste cenário a cibercultura e a inclusão digital. A pesquisa foi realizada através da análise dos projetos pedagógicos de curso (PPC), buscando descritores relacionados à cultura digital nas concepções de curso, perfil do egresso, organização curricular e ementário, configurando uma pesquisa documental. A discussão dos dados demonstra uma concepção difusa sobre tecnologia na maioria dos documentos analisados, bem como a pouca presença de componentes curriculares para abordar a relação das tecnologias digitais na educação. A inexistência de referência aos processos de inclusão digital nos PPC analisados e a perspectiva reducionista e instrumental com que as tecnologias são mencionadas nos processos formativos indicam haver um distanciamento entre a formação inicial docente e o cenário sociotécnico contemporâneo nesta instituição.

Palavras-chave: Tecnologias digitais; Formação docente; Cibercultura; Inclusão digital; Licenciatura.

\section{Teaching initial training: analysis of pedagogical course projects and its relationship to digital technologies}

\begin{abstract}
This paper aims to analyze the curricula of undergraduate courses of a public university in Brazil to understand its relationship to digital technologies. It problematizes the idea that teaching trainings need to be in line to the contemporary conceptions, which includes cyberculture and digital inclusion in such a scenario. This study was conducted through the analysis of the pedagogical course project (PCP), taking into account descriptors relating to digital culture in the conceptions of the courses, undergraduate student profile, curriculum organization, and syllabus, making it a documental research. Its data discussion offers a scattered idea of technology in most of the documents analyzed, as well as a low-level presence of curricula components to address the relationship of digital technology in education. The lack of references to the processes of digital inclusion in the PCP analyzed and the reductionist and instrumental perspective with which technologies are mentioned in training processes suggest that there is a distancing between the teaching initial training and the contemporary sociotechnical scenario in this institution.
\end{abstract}

Keywords: Digital technology; Teaching training; Cyberculture; Digital inclusion; Undergraduate. 


\section{Introdução}

Problematizar a formação inicial de professores diante dos marcadores sociotécnicos contemporâneos é um imperativo atual. O desenvolvimento da cibercultura, potencializado a partir do estabelecimento do ciberespaço, através das tecnologias digitais, em que a "abertura" (CASTELLS, 2003) é a caracterização que implica novas relações no tempo e espaço (CASTELLS, 2007), torna-se um indicador que deve orientar o fazer pedagógico em nossos tempos. Nesse sentido, assumir que a docência precisa estar permeada de saberes que dialoguem com a cibercultura é um princípio da pesquisa desenvolvida para a construção deste texto. O objetivo do artigo é analisar os currículos de cursos de licenciatura de uma universidade pública, a fim de perceber as suas relações com as tecnologias digitais. Para tanto, assume como problematização: Como a formação inicial de professores em uma universidade pública expressa, nos seus projetos de curso, as concepções que envolvem a cibercultura e a inclusão digital? A partir desse questionamento, desenvolvem-se também os conceitos orientadores do estudo.

Inicialmente, a ideia de cibercultura é concebida a partir das discussões de Pierre Lévy, como um "conjunto de técnicas (materiais e intelectuais), de práticas, de atitudes, de modos de pensamento e de valores que se desenvolvem juntamente com o ciberespaço" (LÉVY, 1999, p.17). Embora seja um conceito reconhecido e difundido no âmbito científico, interessa, na pesquisa, perceber se ele permeia os currículos dos cursos de licenciatura analisados.

Juntamente com a concepção de cibercultura, está o conceito de inclusão digital, trazido na perspectiva desenvolvida por Marcon (2015, p.99) como

[...] um processo que fomenta apropriações tecnológicas nas quais os sujeitos são compreendidos como produtores ativos de conhecimento e de cultura, em uma dinâmica reticular que privilegia a vivência de características nucleares na sociedade contemporânea, como a interação, a autoria e a colaboração. Inclusão digital pressupõe o empoderamento por meio das tecnologias, a garantia à equidade social e à valorização da diversidade, suprindo necessidades individuais e coletivas, visando à transformação das próprias condições de existência e o exercício da cidadania na rede.

Dessa maneira, compreender a inclusão digital como um processo mais amplo que o acesso às tecnologias digitais, implica o reconhecimento de que, no campo da formação de professores, é necessário que haja uma concepção curricular implicada na construção desta perspectiva. Em pesquisa anterior (MACHADO, 2016), discutiu-se a ausência de práticas pedagógicas na Educação Básica que contemplassem recursos tecnológicos digitais a partir de princípios da cibercultura: ubiquidade, mobilidade e colaboração. Em geral, nos contextos analisados, diante da inclusão das tecnologias digitais na sala de aula, os docentes reiteram práticas pedagógicas tradicionais. Nesse sentido, a problemática desta pesquisa se volta à ideia do fortalecimento da formação docente a partir de uma perspectiva que corrobore para o desenvolvimento de uma didática alinhada aos princípios do contemporâneo, dialogando com Fantin e Rivoltella (2012), ao apontar que um dos problemas da formação de professores em relação à tecnologia é a formação inicial de docentes, que precisa ser compreendida como a primeira etapa da profissionalização. A profissionalização, que inicia na formação inicial de professores, é percebida como elemento crucial na construção de uma base desta formação:

Caracterizar o papel essencial da formação inicial dos docentes para o desempenho de seu trabalho implica pensar seu impacto na constituição de sua profissionalidade e de sua profissionalização em forma socialmente reconhecida. [...]Não há consistência em uma profissionalização, sem a constituição de uma base sólida de conhecimentos e formas de ação. Daí, a importância de uma sólida formação inicial, solidez que também necessita de 
reconhecimento pelo conjunto societário. (GATTI; BARRETO; ANDRÉ, 2011, p.93)

Articulando as ideias sobre a formação docente na contemporaneidade, Santos (2014, p.28) defende a "inclusão cibercultural dos professores" como um desafio do contexto contemporâneo e que "se consolida como ambiência comunicacional favorável à autoria, compartilhamento, conectividade, colaboração e interatividade". Neste sentido, o olhar para os currículos será voltado à busca de evidências que possam estabelecer esta inclusão cibercultural desde a formação inicial, pensando se os projetos de curso dimensionam tais questões em suas propostas.

Dessa forma, o artigo apresentará, em sua estrutura: o percurso metodológico desenvolvido; os dados produzidos e sua discussão com base nos conceitos orientadores; as considerações finais.

\section{Percurso metodológico}

O recorte aqui apresentado faz parte de uma pesquisa mais ampla, desenvolvida entre 2017 e 2019, intitulada "Formação docente para a cibercultura: análise dos cursos de licenciatura da UNIPAMPA". O estudo se inscreve, então, como uma abordagem qualitativa, do tipo pesquisa documental (SEVERINO, 2016). Os documentos analisados foram os Projetos Pedagógicos de Curso (PPC) dos dezesseis cursos de licenciatura da instituição, vigentes no período de coleta de dados. A análise dos PPC ocorreu através de dois procedimentos.

O primeiro procedimento foi o mapeamento de descritores que compõem as concepções orientadoras da pesquisa: "cibercultura", "inclusão digital", "TIC" (como abreviação de "tecnologias da informação e comunicação"), "tecnologia" e "digital", com variantes de singular e plural. A escolha pelo uso da sigla "TIC" deu-se pela ideia de que a opção abreviada poderia indicar a recorrência do termo ao longo do texto dos PPC. A busca por estes descritores no texto dos PPC excluiu o uso dos termos em contextos diferentes daqueles que estavam voltados à formação docente ou à perspectiva educacional. Para cada expressão encontrada, destacou-se o contexto e seção do documento em que estava descrita e, posteriormente, analisou-se as concepções ali presentes. A análise nesta primeira etapa considerou, fundamentalmente, a presença dos termos na concepção de curso, no perfil do egresso e na organização curricular, definidas como as três seções centrais de um PPC.

O segundo procedimento desenvolvido foi a análise da matriz curricular e ementário, onde buscou-se evidenciar quais componentes curriculares faziam parte do curso e estavam voltados ao tema da inclusão digital ou situados no campo das tecnologias digitais e educação. Para essa segunda análise, foram selecionadas as ementas dos componentes curriculares primeiramente pelo seu título e, num segundo momento, pela busca do descritor "tecnologia" (associada à ideia do uso educacional). A partir disso, todos os componentes curriculares foram analisados (título, ementa e referenciais bibliográficos) e organizados conforme o tipo de oferta em cada matriz curricular, se obrigatórios ou optativos.

Diante destes dois procedimentos, a análise que será desenvolvida pretende discutir os currículos de cursos de licenciatura desta instituição, a partir de três elementos: a concepção de tecnologia presente nos PPC; como os currículos dialogam com o cenário contemporâneo, especialmente a cena sociotécnica da cibercultura; qual a referência aos processos de inclusão digital realizada nos documentos. Estes três elementos, em articulação, foram orientadores da análise interpretativa que segue.

\section{Resultados e discussões}

V. $18 \mathrm{~N}^{\mathrm{o}}$ 1, julho, 2020 RENOTE DOI: 
A instituição analisada possuía, no ano de 2017 (data da coleta dos PPC), dezesseis cursos de licenciatura presenciais em andamento. $\mathrm{O}$ acesso aos documentos foi realizado através dos websites de cada curso, todos vinculados ao website da Pró-Reitoria de Graduação da instituição. Como trata-se de uma instituição multicampi, alguns cursos são ofertados em mais de um campus, com projetos pedagógicos diferentes. Nesse sentido, nos dados aparecem os números (1) e (2) ao lado do nome do curso, para diferenciar o campus de oferta. Ao lado do nome de cada curso apresenta-se, também, o ano em que o PPC entrou em vigência na instituição. É importante destacar, também, que todos os PPC podem ser considerados atuais, tendo em vista que a maioria foi elaborada entre os anos de 2014 e 2016. Quanto aos resultados do primeiro procedimento de pesquisa, a busca pelos descritores mencionados, apresenta-se a Tabela 1 a seguir.

Tabela 1 - Presença ou ausência do descritor nos PPC

\begin{tabular}{|c|c|c|c|c|c|}
\hline & TIC & CIBERCULTURA & TECNOLOGIA & $\begin{array}{l}\text { INCLUSÃO } \\
\text { DIGITAL }\end{array}$ & DIGITAL \\
\hline $\begin{array}{l}\text { Ciências } \\
\text { Biológicas (2013) }\end{array}$ & - & - & - & - & - \\
\hline $\begin{array}{l}\text { Ciências da } \\
\text { Natureza } 1 \text { (2015) }\end{array}$ & - & - & Org. Curricular & - & - \\
\hline $\begin{array}{l}\text { Ciências da } \\
\text { Natureza } 2 \\
(2013)\end{array}$ & - & - & $\begin{array}{c}\text { Concepção de curso } \\
\text { Perfil do egresso } \\
\text { Org. curricular }\end{array}$ & - & - \\
\hline $\begin{array}{l}\text { Ciências Exatas } \\
(2016)\end{array}$ & - & - & $\begin{array}{c}\text { Concepção de curso } \\
\text { Perfil do egresso } \\
\text { Org. curricular }\end{array}$ & - & $\begin{array}{c}\text { Org. } \\
\text { curricular }\end{array}$ \\
\hline $\begin{array}{l}\text { Ciências } \\
\text { Humanas (2014) }\end{array}$ & - & - & Org. curricular & - & - \\
\hline $\begin{array}{l}\text { Educação do } \\
\text { Campo (2016) }\end{array}$ & - & $\begin{array}{l}\text { Organização } \\
\text { curricular }\end{array}$ & $\begin{array}{c}\text { Concepção de curso } \\
\text { Org. curricular }\end{array}$ & - & $\begin{array}{l}\text { Org. } \\
\text { curricular }\end{array}$ \\
\hline $\begin{array}{l}\text { Educação Física } \\
(2012)\end{array}$ & - & - & Concepção de curso & - & - \\
\hline $\begin{array}{l}\text { Física } \\
(2014)\end{array}$ & - & - & Org. curricular & - & - \\
\hline $\begin{array}{l}\text { História } \\
(2016)\end{array}$ & - & - & Org. curricular & - & - \\
\hline $\begin{array}{l}\text { Letras - Português } \\
\text { (2014) }\end{array}$ & - & - & $\begin{array}{c}\text { Concepção de curso } \\
\text { Perfil do egresso } \\
\text { Org. curricular }\end{array}$ & - & - \\
\hline $\begin{array}{l}\text { Letras - } \\
\text { Português e } \\
\text { Espanhol (2010) }\end{array}$ & - & - & Concepção de curso & - & - \\
\hline $\begin{array}{l}\text { Matemática } 1 \\
(2016)\end{array}$ & - & - & Concepção de curso & - & $\begin{array}{l}\text { Org. } \\
\text { curricular }\end{array}$ \\
\hline $\begin{array}{l}\text { Matemática } 2 \\
(2014)\end{array}$ & - & - & $\begin{array}{l}\text { Perfil do egresso } \\
\text { Org. curricular }\end{array}$ & - & - \\
\hline Música (2016) & - & - & Org. curricular & - & $\begin{array}{c}\text { Org. } \\
\text { curricular }\end{array}$ \\
\hline Pedagogia (2015) & - & - & Org. curricular & - & - \\
\hline Química (2016) & - & - & Org. curricular & - & - \\
\hline
\end{tabular}

Os dados evidenciados na Tabela 1 mostram que em nenhum PPC analisado foram encontrados os termos "TIC" e "inclusão digital". Apenas no curso de "Educação do Campo" foi encontrado o termo "cibercultura", utilizado para nomear o contexto

V. $18 \mathrm{~N}^{\circ} 1$, julho, 2020

RENOTE

DOI: 
contemporâneo que necessita de ferramentas de tecnologia da informação e comunicação para organizar os processos de ensino e aprendizagem. Já o termo "digital" aparece em quatro dos dezesseis cursos de licenciatura. Todos foram encontrados na seção referente à organização curricular, descrevendo formas de interação digital que o curso utiliza. Aqui aparecem descrições sobre uso de ambientes virtuais de aprendizagem. A marca mais expressiva referente à análise deste conjunto de dados é justamente a ausência dos termos nos PPC analisados. Nenhuma menção à inclusão digital e apenas uma à cibercultura é o primeiro destaque em relação à discussão pretendida: da insuficiência de uma contextualização do cenário sociotécnico atual na concepção de formação de professores. As ideias de Kenski (2012, p. 47) aparecem como centrais para perceber que não é possível desconsiderar as "mudanças contemporâneas advindas das redes" no campo educacional e, consequentemente, entende-se o mesmo para a formação inicial de professores. Seguindo a análise, a Tabela 2 organiza a distribuição do descritor "tecnologia" nos PPC analisados, conforme as seções do documento em que aparecem nos respectivos cursos.

Tabela 2 - Distribuição do descritor "tecnologia" nos PPC

\begin{tabular}{l|l|l}
\multicolumn{1}{c|}{$\begin{array}{c}\text { CONCEPÇÃO } \\
\text { DE CURSO }\end{array}$} & \multicolumn{1}{c}{$\begin{array}{c}\text { PERFIL DO } \\
\text { EGRESSO }\end{array}$} & \multicolumn{1}{c}{$\begin{array}{c}\text { ORGANIZAÇÃO } \\
\text { CURRICULAR }\end{array}$} \\
\hline Ciências da Natureza 2 (2013) & Ciências da Natureza 2 (2013) & Ciências da Natureza 2 (2013) \\
\hline Ciências Exatas (2016) & Ciências Exatas (2016) & Ciências Exatas (2016) \\
\hline & & Ciências Humanas (2014) \\
\hline Educação do Campo (2016) & & Educação do Campo (2016) \\
\hline Educação Física (2012) & & Física (2014) \\
\hline & & História (2016) \\
\hline Letras - Português (2014) & Letras - Português (2014) & Letras - Português (2014) \\
\hline $\begin{array}{l}\text { Letras - Português e Espanhol } \\
\text { (2010) }\end{array}$ & & \\
\hline Matemática 1 (2016) & & Matemática 2 (2014) \\
\hline & Matemática 2(2014) & Música (2016) \\
\hline & & Pedagogia (2015) \\
\hline
\end{tabular}

Conforme destacado na apresentação dos procedimentos metodológicos, a análise dos PPC considerou, para a busca dos descritores, três seções do documento: a concepção de curso - em que aparecem os objetivos do curso, as linhas ou eixos orientadores do projeto, entre outros; o perfil do egresso - em que se destacam as características esperadas do profissional a ser formado naquela área; e a organização curricular - que dispõe das concepções curriculares do projeto de curso. A Tabela 2 evidencia que o termo tecnologia aparece em todos os PPC, ao menos em uma seção do projeto. Em apenas três dos dezesseis cursos (Ciências da Natureza, Ciências Exatas e Letras - Português) há menção do termo nas três seções destacadas, o que pode ser compreendido como uma característica da profissionalização (GATTI; BARRETO; ANDRÉ, 2011), tendo em vista a ideia de que contemplaria um perfil formativo ligado ao contexto das tecnologias por perpassar os elementos centrais do projeto de curso.

O segundo elemento de destaque é a presença do termo, na maioria dos cursos, na seção que trata da "organização curricular". Destaca-se aqui que desta seção foram excluídas a matriz curricular e o ementário. Nenhum documento ultrapassou três menções do termo na seção. A maioria deles traz o uso da palavra apenas uma vez. Em relação à

V. $18 \mathrm{~N}^{\mathrm{o}}$ 1, julho, 2020

RENOTE

DOI: 
organização curricular, à exceção dos cursos de Ciências Exatas e Educação do Campo, que abordam em seus eixos temáticos a discussão com as tecnologias, os demais cursos apresentam o termo ao mencionar formas de avaliação e comunicação do curso, dando destaque ao ambiente virtual de aprendizagem da instituição (no caso, o Moodle), como oportunidade de uso para o ensino.

Outro elemento importante é o contexto de uso da palavra "tecnologia", que evidencia, também, a sua concepção. Foram encontradas quatro expressões associadas à palavra tecnologia nos documentos: "tecnologias da informação e comunicação", "novas tecnologias", "tecnologias virtuais e digitais" e "tecnologias de comunicação remota". Em nenhum documento foi encontrada alguma definição destas expressões, que pudesse contribuir para a compreensão da concepção teórica e pedagógica ali ensejada. No entanto, a análise sugere que há um uso desprendido de uma concepção aprofundada, visto que, diante das exigências legais para a formação de professores vigentes no período de elaboração dos PPC (BRASIL, 2002; BRASIL, 2006; BRASIL, 2015) é necessário contemplar aspectos ligados às tecnologias como reconhecimento de uma possibilidade de inovação pedagógica na educação.

Na sequência, em relação ao segundo procedimento analítico, serão apresentados os dados referentes às ementas ligadas ao campo das tecnologias digitais encontradas nas matrizes curriculares analisadas. Para a apresentação considerou-se uma síntese de cada ementa analisada, além de indicar o tipo de oferta do componente curricular, se obrigatório ou optativo.

Tabela 3 - Componentes curriculares vinculados às tecnologias digitais

\begin{tabular}{|c|c|c|c|}
\hline CURSO & $\begin{array}{c}\text { NOME DO } \\
\text { COMPONENTE } \\
\text { CURRICULAR }\end{array}$ & TIPO DE OFERTA & SÍNTESE \\
\hline $\begin{array}{l}\text { Ciências da Natureza (2) } \\
\text { (2013) }\end{array}$ & Educação e Mídia & Obrigatório & $\begin{array}{l}\text { Interação, construção } \\
\text { coletiva de } \\
\text { conhecimento por meio } \\
\text { da internet }\end{array}$ \\
\hline Ciências Exatas (2016) & Robótica educacional & Obrigatório & $\begin{array}{l}\text { Educação e tecnologia; } \\
\text { Criação de atividades } \\
\text { para o ensino e } \\
\text { aprendizagem }\end{array}$ \\
\hline Ciências Exatas (2016) & $\begin{array}{l}\text { Tecnologias para o } \\
\text { Ensino de Ciências }\end{array}$ & Obrigatório & $\begin{array}{l}\text { Softwares e recursos da } \\
\text { internet para o ensino } \\
\text { de Ciências }\end{array}$ \\
\hline $\begin{array}{l}\text { Educação do Campo } \\
\text { (2016) }\end{array}$ & Letramento Digital & Obrigatório & $\begin{array}{l}\text { Práticas letradas no } \\
\text { meio digital; } \\
\text { Ferramentas da internet }\end{array}$ \\
\hline $\begin{array}{l}\text { Educação do Campo } \\
\text { (2016) }\end{array}$ & $\begin{array}{l}\text { Tecnologias digitais e } \\
\text { produção de materiais }\end{array}$ & Obrigatório & $\begin{array}{l}\text { Produção de materiais } \\
\text { digitais para o ensino } \\
\text { de Ciências }\end{array}$ \\
\hline Educação Física (2012) & $\begin{array}{l}\text { Educação Física e } \\
\text { Mídia }\end{array}$ & Obrigatório & $\begin{array}{l}\text { Produção e utilização } \\
\text { das TICs no } \\
\text { ensino/aprendizagem }\end{array}$ \\
\hline Física (2014) & $\begin{array}{l}\text { Instrumentação para } \\
\text { o Ensino de Física II }\end{array}$ & Obrigatório & $\begin{array}{l}\text { Uso de TICs no ensino } \\
\text { de Física }\end{array}$ \\
\hline História (2016) & $\begin{array}{l}\text { Tecnologias da } \\
\text { Informação e da } \\
\text { Comunicação } \\
\text { aplicadas ao Ensino }\end{array}$ & Complementar & $\begin{array}{l}\text { Tecnologias digitais } \\
\text { integradas à docência }\end{array}$ \\
\hline Matemática (1) (2016) & $\begin{array}{l}\text { Informática na } \\
\text { Educação } \\
\text { Matemática }\end{array}$ & Obrigatório & $\begin{array}{l}\text { Softwares educativos; } \\
\text { uso de novas } \\
\text { tecnologias no ensino } \\
\text { de Matemática }\end{array}$ \\
\hline
\end{tabular}

V. $18 \mathrm{~N}^{\mathrm{o}} 1$, julho, 2020 RENOTE

DOI: 


\begin{tabular}{|c|c|c|c|}
\hline Matemática (2) (2014) & $\begin{array}{l}\text { Tecnologias } \\
\text { aplicadas ao Ensino } \\
\text { da Matemática }\end{array}$ & Complementar & $\begin{array}{l}\text { Uso de tecnologias } \\
\text { para o ensino de } \\
\text { Matemática }\end{array}$ \\
\hline Música (2016) & $\begin{array}{l}\text { Tecnologias } \\
\text { aplicadas à educação } \\
\text { musical I }\end{array}$ & Complementar & $\begin{array}{l}\text { Uso dos recursos } \\
\text { tecnológicos no ensino } \\
\text { de Música }\end{array}$ \\
\hline Música (2016) & $\begin{array}{l}\text { Tecnologias } \\
\text { aplicadas à educação } \\
\text { musical II }\end{array}$ & Complementar & $\begin{array}{l}\text { Produção de materiais } \\
\text { didáticos a partir dos } \\
\text { recursos tecnológicos }\end{array}$ \\
\hline Pedagogia (2015) & Mídias e Educação & Obrigatório & $\begin{array}{l}\text { Educação, } \\
\text { comunicação e } \\
\text { tecnologia }\end{array}$ \\
\hline Química (2016) & $\begin{array}{l}\text { Tecnologias da } \\
\text { Informação e } \\
\text { Comunicação no } \\
\text { Ensino de Química }\end{array}$ & Complementar & $\begin{array}{l}\text { Softwares e sites para o } \\
\text { ensino de Química e } \\
\text { Ciências }\end{array}$ \\
\hline
\end{tabular}

Dos dezesseis projetos de curso analisados, em apenas onze foram encontrados, na matriz curricular, algum componente curricular vinculado ao campo das tecnologias digitais. Isso significa que, em cinco cursos, o PPC não apresenta ao menos um espaço formativo para problematizar as questões ligadas ao ensino e às tecnologias. Analisando o tipo de oferta, o contexto fica ainda mais comprometido: dos dezesseis cursos, em apenas sete há oferta de componentes curriculares obrigatórios. E, em apenas dois cursos (Ciências Exatas e Educação do Campo) há mais de um componente curricular obrigatório vinculado à temática. $\mathrm{O}$ destaque para a oferta dos componentes curriculares obrigatórios indica a garantia de que os estudantes terão a oportunidade de desenvolver a discussão em algum momento de sua formação. Se o componente curricular é optativo, será cursado por escolha individual de cada estudante (e se houver oferta). Portanto, não há garantia de que terão contato com o tema. Quanto à síntese das ementas, chama a atenção o destaque para a discussão das tecnologias de um ponto de vista metodológico e instrumental. Na maioria dos cursos há menção da relação entre "uso" da tecnologia e "ensino". A análise evidencia que há, aqui, uma concepção reducionista da tecnologia, considerada como ferramenta, numa perspectiva instrumental.

Tal perspectiva é discutida por Alonso et al. (2014, pp. 155-156), especialmente na relação entre a formação de professores e as práticas escolares com tecnologias digitais:

\begin{abstract}
Nos últimos anos, problematizações e propostas sobre o aprender e ensinar escolar, a formação de professores, seja ela inicial ou continuada, têm fomentado algumas "saídas" para o "uso pedagógico", como denominado por várias iniciativas governamentais, das TDIC nas escolas. O maior problema de tais iniciativas tem a ver, sobretudo, com o pensamento, ainda reducionista, de que bastaria trabalhar algumas competências/habilidades técnicas para que estas tecnologias fossem mais bem aproveitadas no cotidiano dos estabelecimentos escolares.
\end{abstract}

Ainda que seja importante, no contexto da formação inicial, conhecer ferramentas e desenvolver competências para o seu uso, a defesa feita nesta análise é de que não basta uma apropriação instrumental para que haja um desenvolvimento pedagógico qualificado. Conjuntamente com a ideia de "uso" faz-se necessária a reflexão sobre tais usos, suas implicações pedagógicas, sociais, culturais em relação aos processos, tal qual o conceito de inclusão digital apresentado anteriormente. Neste sentido, Souza e Bonilla (2014, p.2728) complementam a análise:

Destacamos que mais do que o acesso e o uso isolado das tecnologias digitais por esta ou aquela disciplina, como vem acontecendo na maioria das 
instituições de ensino, é necessário que exista, na proposta curricular desses cursos, direcionados aos educadores, a possibilidade de incorporar as questões relacionadas à cultura digital, vivenciando os diversos espaços que já fazem parte do nosso cotidiano, tais como os blogs, as redes sociais, os sites de compartilhamento de vídeos online, os jogos online, ou seja, espaços plurais que, ao serem incorporados na educação, vão requerer do professor uma postura muito mais aberta, ativa e propositiva. Por isso, torna-se fundamental que os processos formativos sejam mais do que mera transferência de informação.

Assim, o projeto pedagógico de curso de licenciatura é compreendido nesta pesquisa como o documento que expressa as concepções centrais para a profissionalização docente, e orienta as ações formativas. Neste sentido, considera-se necessário que este currículo seja representativo das demandas contemporâneas, e possa convergir para a produção de conhecimento alinhada a esse cenário. A análise empreendida nestes documentos vai ao encontro da discussão desenvolvida por Pretto (2011, p.108-109):

O currículo continua sendo uma grade, mesmo quando é denominado com outras palavras. Mantém-se, assim, o currículo baseado numa lógica vertical, linear, centrada na ordem, contraditório com tudo que se faz contemporaneamente nas demais áreas do conhecimento, notadamente no campo da pesquisa e da produção do conhecimento. Dessa forma, passa o currículo a assumir o papel de regulador desses processos.

Assumindo o currículo como um documento orientador importante para os processos formativos, regulador dos processos educacionais, entende-se que não há evidências de uma relação com a cibercultura em relação aos documentos analisados. Isso não significa dizer que as práticas formativas não contemplem tais dimensões, mas para o foco da discussão aqui empreendida, não há materialidade suficiente nos documentos que possa acenar para a relação entre o currículo e a pesquisa e produção de conhecimentos vinculados à cultura digital.

\section{Considerações Finais}

O artigo se propôs a analisar os currículos de cursos de licenciatura de uma universidade pública, a fim de perceber as suas relações com as tecnologias digitais. Para tanto, a pesquisa documental realizada em dezesseis cursos de licenciatura de uma instituição, foi construída procurando destacar três elementos analíticos dos seus PPC: a concepção de tecnologia presente nos PPC; como os currículos dialogam com o cenário contemporâneo; qual a referência aos processos de inclusão digital realizada nos documentos.

Em relação à concepção de tecnologia presente nos PPC analisados, em função das nomeações distintas apresentadas, e sem aprofundamento conceitual nos próprios documentos, que esclarecessem o seu uso e contextualização, defende-se que há uma concepção difusa em relação à tecnologia nos documentos. Apenas em um dos PPC analisados (Educação do Campo) aparece uma discussão sobre cibercultura, que explica o conceito. Nos demais, as menções não dialogam com a sua compreensão e, tomadas como definições estabelecidas, podem até ser problematizadas, tais quais as ideias de "novas tecnologias" (que não se caracterizam como "educacionais") e "tecnologias de comunicação remota". A expressão "tecnologias de informação e comunicação" é a mais utilizada, ainda que pareça por uma necessidade de responder às questões previstas nas diretrizes curriculares para formação de professores do que propriamente como um 
aprofundamento na sua concepção. Com a instituição da Base Nacional Comum Curricular (BRASIL, 2017) e da Base Nacional Comum para a Formação Inicial de professores (BRASIL, 2019), estima-se que tais currículos sejam revistos, pois nestas normativas as tecnologias digitais ocupam lugar de destaque.

Tendo em vista a ideia da relação do currículo com o cenário contemporâneo, propriamente a cena sociotécnica que a cibercultura nos coloca, evidencia-se que os currículos não preconizam o reconhecimento do contexto da cultura digital, ao qual seus sujeitos estão imersos, e as possibilidades de articulação com o currículo escolar atualizado pelas demandas deste tempo. Daí a necessidade de construção de currículos mais dinâmicos em relação às tecnologias, que dialoguem com outras realidades culturais, territoriais e educacionais.

Quanto ao terceiro enfoque de análise, não foi encontrada nenhuma menção à inclusão digital nos PPC analisados. Retomando a concepção de Marcon (2015), a discussão sobre inclusão digital num currículo de formação de professores, é defendida como a possibilidade de construção do empoderamento por meio das tecnologias e, com isso possibilidades de garantia à equidade social, à valorização da diversidade de sujeitos e do exercício da cidadania em rede.

A inexistência de referência aos processos de inclusão digital nos PPC analisados, bem como a perspectiva reducionista e instrumental com que as tecnologias são mencionadas nos processos formativos, indicam que há um distanciamento entre a formação inicial docente e o cenário sociotécnico contemporâneo nesta instituição. E este é um desafio para a problematização nos diferentes contextos, da possibilidade de uma reconstrução de concepções e práticas que possam responder às demandas educacionais do nosso tempo.

\section{Referências Bibliográficas}

ALONSO, Katia Morosov; ARAGÓN, Rosane; SILVA, Danilo Garcia da; CHARCZUK, Simone Bicca. Aprender e ensinar em tempos de Cultura Digital. EmRede - Revista de Educação a Distância. v.1, n.1, 2014. p.152-168.

BRASIL. Conselho Nacional de Educação. Institui Diretrizes Curriculares Nacionais para a Formação de Professores da Educação Básica, em nível superior, curso de licenciatura, de graduação plena. Resolução CNE/CP n.01/2002. Brasília, Diário Oficial da República Federativa do Brasil, 9 de abril de 2002. Seção 1, p. 31. Disponível em: http://portal.mec.gov.br/cne/arquivos/pdf/rcp01_02.pdf . Acesso em 23 mai 2020.

BRASIL. Conselho Nacional de Educação. Institui Diretrizes Curriculares Nacionais para o Curso de Graduação em Pedagogia, licenciatura. Resolução CNE/CP n.01/2006. Brasília, Diário Oficial da República Federativa do Brasil, 16 de maio de 2006, Seção 1, p. 11. Disponível em: http://portal.mec.gov.br/cne/arquivos/pdf/rcp01_06.pdf. Acesso em 23 mai 2020.

BRASIL. Conselho Nacional de Educação. Define as Diretrizes Curriculares Nacionais para a formação inicial em nível superior (cursos de licenciatura, cursos de formação pedagógica para graduados e cursos de segunda licenciatura) e para a formação continuada. Resolução CNE/CP n.02/2015. Brasília, Diário Oficial da República Federativa do Brasil, 2 de julho de 2015 - Seção 1 - pp. 8-12. Disponível em: http://portal.mec.gov.br/docman/agosto-2017-pdf/70431-res-cne-cp-002-03072015pdf/file . Acesso em 23 mai 2020.

V. $18 \mathrm{~N}^{\circ} 1$, julho, 2020 RENOTE DOI: 
BRASIL. Conselho Nacional de Educação. Institui e orienta a implantação da Base Nacional Comum Curricular, a ser respeitada obrigatoriamente ao longo das etapas e respectivas modalidades no âmbito da Educação Básica. Resolução CNE/CP n.02/2017. Brasília, Diário Oficial da República Federativa do Brasil, 22 de dezembro de 2017 $\begin{array}{lllllll}\text { Seção } & 1 & - & \text { pp. } & 41-44 . & \text { Disponível }\end{array}$ http://basenacionalcomum.mec.gov.br/images/historico/RESOLUCAOCNE_CP222DE DEZEMBRODE2017.pdf. Acesso em 24 jul 2020.

BRASIL. Conselho Nacional de Educação. Define as Diretrizes Curriculares Nacionais para a Formação Inicial de Professores para a Educação Básica e institui a Base Nacional Comum para a Formação Inicial de Professores da Educação Básica (BNC-Formação). Resolução CNE/CP n.02/2019. Brasília, Diário Oficial da República Federativa do Brasil, 15 de abril de 2019 - Seção 1 - pp. 46-49. Disponível em: http://portal.mec.gov.br/docman/dezembro-2019-pdf/135951-rcp002-19/file. Acesso em 24 jul 2020.

CASTELLS, Manuel. A Galáxia da Internet. Rio de Janeiro: Zahar, 2003.

CASTELLS, Manuel. A Sociedade em Rede. São Paulo: Paz e Terra, 2007.

FANTIN, Monica; RIVOLTELLA, Pier Cesare. Cultura digital e formação de professores: usos da mídia, práticas culturais e desafios educativos. In: FANTIN, M.; RIVOLTELLA, P.C. Cultura digital e escola: pesquisa e formação de professores. São Paulo: Papirus, 2012. p.95-146.

GATTI, Bernardete Angelina; BARRETO, Elba Siqueira de Sá; ANDRÉ, Marli. Políticas docentes no Brasil: um estado da arte. Brasília: UNESCO, 2011.

KENSKI, Vani Moreira. Educação e Tecnologias: o novo ritmo da informação. Campinas: Papirus, 2012.

LÉVY, Pierre. Cibercultura. São Paulo: Ed.34, 2007.

MACHADO, Juliana B. Os desafios da formação docente no contexto da inclusão digital: análise de práticas pedagógicas. In: XI Reunião Científica da Região Sul - ANPED Sul. Curitiba: UFPR, 2016.

MARCON, Karina. A inclusão digital na formação inicial de educadores a distância: estudo multicaso nas universidades abertas do Brasil e de Portugal. 2015. Tese (Doutorado em Educação). Programa de Pós-Graduação em Educação, Universidade Federal do Rio Grande do Sul, 2015.

PRETTO, Nelson de Luca. O desafio de educar na era digital: educações. In: Revista Portuguesa de Educação, vol. 24, núm. 1, 2011, p. 95-118.

SANTOS, Edméa. Pesquisa-formação na cibercultura. Santo Tirso: White Books, 2014.

SEVERINO, Antônio Joaquim. Metodologia do trabalho científico. São Paulo: Cortez, 2016.

SOUZA, J. S. DE; BONILLA, M. H. S. A cultura digital na formação de professores. Revista Tempos e Espaços em Educação, p. 23-34, 30 dez. 2014. 